\title{
Criminologie
}

\section{Éditorial : la criminologie et la recherche sur les tribunaux}

\section{Pierre Landreville}

Volume 24, numéro 2, 1991

Regard sur les tribunaux

URI : https://id.erudit.org/iderudit/017306ar

DOI : https://doi.org/10.7202/017306ar

Aller au sommaire du numéro

Éditeur(s)

Les Presses de l'Université de Montréal

ISSN

0316-0041 (imprimé)

1492-1367 (numérique)

Découvrir la revue

Citer ce document

Landreville, P. (1991). Éditorial : la criminologie et la recherche sur les tribunaux. Criminologie, 24(2), 3-4. https://doi.org/10.7202/017306ar d'utilisation que vous pouvez consulter en ligne.

https://apropos.erudit.org/fr/usagers/politique-dutilisation/ 
ÉDITORIAL

LA CRIMINOLOGIE ET LA RECHERCHE SUR LES TRIBUNAUX Pierre Landreville*

En 1985, Pierre Robert écrivait, dans la note liminaire du chapitre «La cour et le procès: réflexions sur la recherche empirique en droit pénal canadien» de La Criminologie empirique au Québec: «Un bilan honnête doit constater [...] la rareté de la recherche empirique appliquée au procès et aux institutions juridiques» (p. 313). Dans ce constat, Pierre Robert tenait compte de la production canadienne, mais le bilan était encore plus pauvre si on s'en tenait uniquement aux recherches effectuées au Québec. On doit aussi remarquer que ces recherches ont surtout été effectuées par des sociologues ou des juristes plutôt que par des criminologues.

Comment expliquer cette indifférence des premiers criminologues québécois pour le fonctionnement des tribunaux? D'une part, durant les années 1960 et 1970, la criminologie d'ici est presque exclusivement une criminologie étiologique axée sur la conduite criminelle, ses causes et les caractéristiques de la personnalité criminelle. Les démarches de recherche se font aussi surtout dans une perspective «correctionnaliste», selon l'expression de Matza (1969). La recherche vise avant tout à mieux combattre le crime. On tente de connaître le criminel pour mieux le traiter et pour mieux prévenir les comportements délictueux. On s'intéresse surtout à la prison pour mieux la transformer et améliorer son efficacité. L'accent est aussi mis sur les "recherches évaluatives». D'autre part, les juristes sont peu enclins à laisser les criminologues observer et étudier leurs pratiques.

Mais la criminologie québécoise s'est elle aussi diversifiée et on a, petit à petit, commencé à poser d'autres questions à la réalité. Au lieu de se demander uniquement: «Pourquoi devient-on délinquant?», on a ajouté ou on a substitué la question: «Pourquoi est-on défini comme délinquant?» et on s'est intéressé à d'autres institutions pénales que la prison. La police puis les tribunaux et l'application de la loi en général sont devenus des objets d'étude. Le fonctionnement du système pénal, le processus de production des délinquants ont été conçus comme des processus sociaux. Ce type de recherche est cependant relativement récent au Québec, surtout en criminologie, de sorte que le champ est encore à peu près vierge et les recherches souvent à des stades exploratoires et plutôt descriptifs.

* Professeur, École de criminologie, Université de Montréal, C.P. 6128, Succ. A, Montréal (Québec) H3C 3J7. 
Le domaine de recherche est pourtant très vaste. En premier lieu, on ne connaît à peu près rien des contentieux traités par les divers tribunaux pénaux au Québec, ni surtout de la manière dont ils sont traités. Des études pourraient nous informer sur le type des affaires acheminées aux tribunaux et sur la sélection et la ventilation effectuées aux divers stades du processus. On pourrait aussi comprendre comment s'effectuent les diverses prises de décisions, quels sont le rôle et le poids des différents acteurs (accusés, policiers, procureurs, avocats, juges). Dans une sociologie du système pénal, il faudrait aussi comprendre l'importance relative de ce qu'on a appelé les facteurs légaux et celle des facteurs extra-légaux dans les prises de décisions. En effet, en plus des facteurs qui doivent être pris en compte selon la doctrine légale, d'autres facteurs bureaucratiques, idéologiques et sociaux tels les caractéristiques des parties (accusés et victimes) et les rapports entre elles doivent être étudiés pour saisir le fonctionnement réel des appareils pénaux.

Ce sont là quelques pistes, quelques dimensions qui devront être explorées si on veut saisir comment sont construits le délinquant et le crime et si on veut élaborer ce que Black (1989) a appelé une «micro-sociologie du droit». Car comme il ajoute lui-même: «Legal doctrine alone cannot adequately predict or explain how cases are handled» (p. 6).

C'est à cette entreprise que les chercheurs qui présentent leurs recherches dans ce numéro de Criminologie se sont attaqués. Il faut espérer que leurs travaux de pionnjers ne sont que les premières pierres d'un chantier beaucoup plus considérable sur le fonctionnement des tribunaux et du système pénal au Québec et qu'ils donneront lieu à des contributions théoriques très attendues sur la sociologie du droit pénal.

\section{Références:}

BLACK, D. (1989), Sociological Justice, Oxford, Oxford University Press.

SZABO, D. et LEBLANC, M. (1985), La Criminologie empirique au Québec, Montréal, P.U.M. 